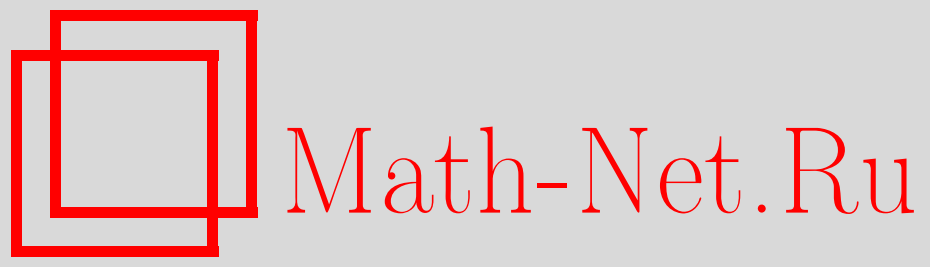

А. Стасенко, Радиоактивный распад, банковский процент и другие, Квант, 2018, номер 8, 30-31

DOI: https://doi.org/10.4213/kvant20180804

Использование Общероссийского математического портала Math-Net.Ru подразумевает, что вы прочитали и согласны с пользовательским соглашением http://www . mathnet.ru/rus/agreement

Параметры загрузки:

IP: 34.239 .49 .27

26 апреля 2023 г., 11:54:52

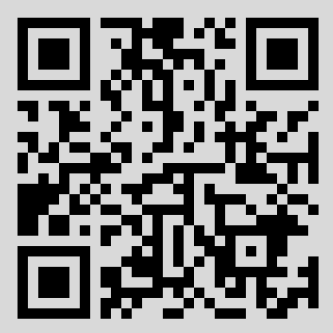




\section{Радиоактивный распаД, банкОВСКИй процент и другие}

\section{A. CTACEHKO}

АК ИЗВЕСТНО, ЯДРА РАДИОАКТИВНОго вещества рано или поздно распадаются с учетом всех законов физики - сохранения массы-энергии, импульса, момента импульса, суммарного электрического заряда, четности... На то они и радиоактивные. Но что значит «рано или поздно»? Для ответа на этот вопрос физиками введена специальная величина - период полураспада $\tau_{1 / 2}$. Уже сам индекс говорит о том, что за это время испытывает превращение половина ядер.

При этом физики записывают вполне разумное выражение того факта, что изменение количества ядер $\Delta n$ за время $\Delta t$ пропорционально их количеству до распада:

$$
\Delta n=-\alpha n \Delta t .
$$

Здесь $\alpha$ - коэффициент пропорциональности, имеющий размерность $1 / \mathrm{c}$, как легко видеть. А знак «минус» свидетельствует об уменьшении прежнего количества рассматриваемого вещества. Считается, что формулировка (1) закона радиоактивного распада принадлежит Фредерику Содди (1877-1956) и Эрнесту Резерфорду (1871-1937).

Решение уравнения (1) известно:

$$
n=n_{0} e^{-\alpha t},
$$

где $e=2,73 \ldots$ - основание натуральных логарифмов, фундаментальная физико-математическая константа. Видно, что в течение отрезка времени $\frac{1}{\alpha}=\tau_{e}$ концентрация ядер уменьшается в $e$ раз (см. рисунок). Легко установить связь между $\tau_{1 / 2}$ и $\tau_{e}$ :

$$
\tau_{e}=\frac{\tau_{1 / 2}}{\ln 2} \approx \frac{\tau_{1 / 2}}{0,7} .
$$

DOI: https://doi.org/10.4213/kvant20180804
Ясно, что это величины одного порядка. Их значение изменяется от $10^{-9}$ до многих миллиардов лет - сравните с современным значением возраста Вселенной 13,7 миллиардов лет.

Интересно, что такой же зависимостью (1) описывается изменение денежного вклада в банк (на начальном этапе), только вместо «минус $\alpha$ »ужно поставить «плюс альфа», где $\alpha$ - теперь уже банковский процент (например, $\alpha=10 \%=0,1)$. Почему «на начальном этапе»? Потому, что существует время, за которое любой скромный вклад $n_{0}$ вырастает до значения, превышающего все богатства Земли, так что уравнение (1) нужно будет заблаговременно дополнить другими слагаемыми, описывающими обратную связь с обществом.

Еще более интересно, что такой же зависимостью (1) описывается и рост числа бактерий или амеб, размножающихся в стеклянной банке делением пополам. Опять же на начальном этапе - ибо объем банки не бесконечен.

Лет двести тому назад подобным фактом был встревожен английский ученый и священник Томас Роберт Мальтус (1766-1834). По его мнению, рост численности человечества должен описываться законом $n=n_{0} e^{t / \tau}$, где $\tau$ есть характерное время порядка 25 лет - это время удвоения численности населения в идеальных условиях. А встревожило его то, что количество продуктов питания растет в арифметической прогрессии (т.е. пропорционально времени), а народонаселение - в геометрической прогрессии, и рано или поздно две соответствующие линии пересекутся (см. рисунок - кружок на штрих-пунктирной кривой) и наступит глобальный голод. Да и просто места на Земле может не хватить!

Дальше еще интереснее. Представим себе микрокапли, падающие в облаке и сливающиеся друг с другом Их концентрация должна убывать по закону

$$
\Delta n=-\beta n(n-1) \Delta t .
$$

Множитель $(n-1)$ учитывает тот факт, что при $n=1 \Delta n=0$ - сливаться не с кем. (Это напоминает историю о встрече группы старых одноклассников, каждый из которых пожал руку другу. Если одноклассников было $N$, любой из них пожал $N-1$ рук, 


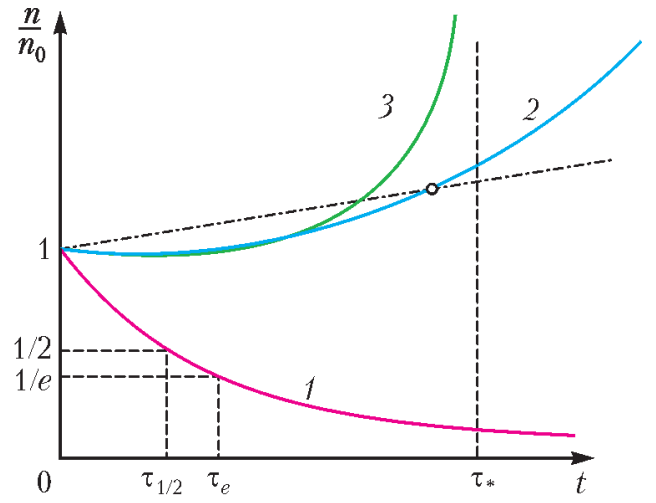

исключая самого себя. И это произошло с каждым, поэтому общее число рукопожатий было $(N-1) \cdot N=99 \cdot 100=9,9 \cdot 10^{3}$.) Но при $n \gg 1$ получим $n(n-1)=n^{2}$, что облегчает интегрирование уравнения (3):

$$
\frac{n}{n_{0}}=\frac{1}{1+n_{0} \beta t} .
$$

Видно, что с течением времени коагуляция капель падает и при $\tau_{1 / 2}=\frac{1}{n_{0} \beta}$ увеличивается в два раза - процесс, обратный полураспаду ядер.

Очевидно, тем же выражением (3) можно описать уменьшение числа пауков в банке, пожирающих друг друга, или убыль числа автомобилей (если прекратить их выпуск) за счет парных столкновений. Или рост концентрации нейтральных частиц в плазме за счет реконбинации - соединения электронов и положительных ионов:

$$
\frac{\Delta n}{\Delta t} \sim n_{+} \cdot n_{-} .
$$

Так как в квазинейтральной плазме концентрации частиц обоих знаков одинаковы: $n_{+}=\frac{n}{2}, n_{-}=\frac{n}{2}$, или $\frac{\Delta n}{\Delta t} \sim n^{2}$, в решении (4) нужно лишь заменить знак $\beta$ на противоположный.

А что же народонаселение? Конечно, эволюцию правильнее описывать уравнениями (3) и (4) (а не $(1,2))$, в которых нужно не забыть изменить знак $\beta$. Но тогда в знаменателе выражения (4) появится знак «минус» и при стремлении времени к значению $\tau_{*}=\frac{1}{n_{0} \beta}$ наступит то, что математики называют страшными словами «градиентная ка-
Качественное описание временно́й эволюции различных "сообществ»:

1 - закон радиоактивного распада или убыль вещества в химической реакции первого порядка;

2 - рост банковского вклада, числа делящихся бактерий или амеб, закон Мальтуса роста народонаселения;

3 - рост числа участников парного взаимодействия, химическая реакция второго порядка. Штрих-пунктирная линия - рост средств потребления, по Мальтусу

тастрофа»: значение $\frac{n}{n_{0}}$ устремляется к бесконечности еще резче, чем в законе Мальтуса!

Разумеется, в современной теоретической демографии в рассмотренных здесь уравнениях появляются дополнительные слагаемые, учитывающие многие факторы (обратное влияние истощения ресурсов, естественную смену поколений...)

Упомянем еще, что законы (1) и (3) используются и в физической химии для описания реакций первого, второго порядков. А еще... Но и сказанного достаточно, чтобы вспомнить вдохновляющие слова средневекового ученого о необозримости физики:

«К физике принадлежит учение о небеcax, о стихиях (элементах) и их движении, о возникновении и уничтожении, о влиянии небес на погоду (метеорология), о минералах, растениях, животных, о душе и ее способностях. Медицина, астрология, учение о талисманах, алхимия, толкование снов и волшебства представляют собой разновидности прикладной физики» (В.В. Соколов. Средневековая философия. - М.: Высшая школа, 1979).

Не случайны и в гимне МФТИ такие слова: «Только в физике соль...»! 